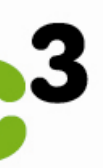

BASQUE CENTRE

FOR CLIMATE CHANGE

Klima Aldaketa Ikergai

\title{
Energy Supply and the Sustainability of Endogenous Growth
}

\author{
Karen Pittel
}

Dirk Rübbelke

July 2010

BC3 WORKING PAPER SERIES

2010-10 
The Basque Centre for Climate Change (BC3) is a Research Centre based in the Basque Country, which aims at contributing to long-term research on the causes and consequences of Climate Change in order to foster the creation of knowledge in this multidisciplinary science.

The BC3 promotes a highly-qualified team of researchers with the primary objective of achieving excellence in research, training and dissemination. The Scientific Plan of BC3 is led by the Scientific Director, Prof. Anil Markandya.

The core research avenues are:

- $\quad$ Adaptation to and the impacts of climate change

- $\quad$ Measures to mitigate the amount of climate change experienced

- International Dimensions of Climate Policy

- $\quad$ Developing and supporting research that informs climate policy in the Basque Country

See www.bc3research.org for further details.

The BC3 Working Paper Series is available on the internet at http://www.bc3research.org/working_papers/view.html

Enquiries (Regarding the BC3 Working Paper Series):

Roger Fouquet

Email: roger.fouquet@bc3research.org

The opinions expressed in this working paper do not necessarily reflect the position of Basque Centre for Climate Change (BC3) as a whole.

Note: If printed, please remember to print on both sides. Also, perhaps try two pages on one side. 


\title{
Energy Supply and the Sustainability of Endogenous Growth*
}

\author{
Karen Pittel** and Dirk Rübbelke***
}

The paper provides an introduction to energy, respective resource, use within the framework of endogenous growth models. We provide an overview of different modeling approaches as well as intuition with respect to the results obtained. We consider the source problem, i.e. the supply of energy, as well as the sink problem, i.e. pollution generated by the consumption of energy resources. The introduction to the theoretical framework shortly discusses the use of neoclassical versus endogenous growth models and also points to the implications of the different types of endogenous growth approaches. We additionally give an introduction to CGE-models that include energy use and present an example of a numerical solvable model in detail. The paper closes with an outlook on future research.

Keywords: endogenous growth, energy, resources, pollution, CGE-models JEL: Q1, Q3, Q4, O4

* The final version of this paper is destined to be published as: Pittel, K. and D. Rübbelke (2011, forthcoming), "Energy Supply and the Sustainability of Endogenous Growth" in I. Galarraga, M. González-Eguino and A. Markandya (eds.), Handbook of Sustainable Use of Energy, Edward Elgar Publications, Cheltenham, UK, and Northampton, MA, USA.

** Karen Pittel, ETH Zurich, CER-ETH Center of economic Research, Zurichbergstr. 18, CH-8092 Zurich, email: kpittel@ethz.ch

*** Basque Centre for Climate Change (BC3), Gran Via, 35-2, 48009, Bilbao, Spain, email: ruebbelke@bc3research.org, and IKERBASQUE, Basque Foundation for Science, 48011, Bilbao, Spain. 


\section{Introduction}

Regarding the use of energy as an input two threats to sustainability are regularly highlighted: the source problem, i.e. the supply of energy, and the sink problem, i.e. pollution generated by the consumption of energy resources. Ever since the Club of Rome's publication of the "Limits to Growth" and the first oil crisis these problems have been discussed extensively in the economics literature. Empirical and theoretical analyses, static as well as dynamic approaches can be found in abundance, some of them featuring up to hundreds of equations and restrictions while others are highly stylized, analytically solvable models with only a handful of mathematical relations. All of these approaches have merits and shortcomings which are dealt with extensively in Edenhofer et al. (2006). The number of approaches used in the discussion mirror clearly the complexity of the issues at hand. In this paper we will focus on especially one strand of the related literature: endogenous growth models that deal with the source and sink problems of energy respective resource use. As energy supply as well as sustainable development - i.e. non-decreasing welfare over time - give rise to intertemporal problems, employing dynamic approaches whose focus is on the very long-run seems straightforward. A look at the literature indeed shows that ever since the "Limits to Growth" (Meadows et al. 1972), growth models have been used to identify conditions under which sustainable development is technically feasible and optimal over a long time horizon.

In the beginning of the 1970s the focus was primarily on the input and optimal timing of resource use. The aim was to derive dynamic allocation rules as a prerequisite for sustainable development, i.e. non-decreasing welfare. However, the consequences of resource use and economic activities on environmental systems in the form of pollution and waste were initially of secondary interest. It was only in the course of increasing environmental degradation that the focus changed. Nevertheless, the interest in the field dwindled over time as the methodological tools applied, specifically those of neoclassical growth theory, were quite unsatisfactory. Especially two aspects finally induced a revival of this line of research. On the one hand, new research fields were identified due to a formerly unknown scale of repercussions of anthropogenic activities on the environment (for example climate change). On the other hand, more sophisticated methodological approaches like the endogenous growth theory were developed that enabled researchers to reconsider and re-evaluate some of the rather strict results formerly derived.

In contrast to the neoclassical growth literature, endogenous growth approaches allow for a feedback effect of energy shortages and pollution induced productivity and welfare losses on the long-run growth performance of an economy. In neoclassical growth 
models, long-run growth is essentially driven by exogenous technological development. Thus feedback effects of resource scarcity and environmental externalities on the growth engine - the ultimate source of the dynamic development of an economy - do not arise. Overcoming this shortcoming by determining the rate of long-run growth within the model was the main contribution of the so-called 'New Growth Revolution'. By introducing non-rivalry of knowledge, learning and imperfect competition, endogenous growth models resolved the problem of decreasing returns to capital which is at the core of the failure to sustain long-run endogenous growth. The induced increase in the explanatory power of the new generation of growth models not only revived the dwindling interest in the overall growth literature, but also allowed a more satisfying analysis of the effects triggered by resource scarcity, i.e. energy shortages, and pollution on the long-run development of economies.

In the first decade after the new growth revolution, endogenous engines of growth were mainly considered in highly stylized and analytically solvable growth models. The merits of these approaches lie mainly in their ability to delineate clearly the dynamic channels through which energy and resource scarcity impact long-run development and growth. Effects of decreasing energy inputs and rising energy prices on, for example, the speed and direction of technological development can be understood as well as the repercussions of pollution externalities on the incentives to accumulate capital and conduct research.

The drawback to this traceability is the restricted modeling scope. The derivation of closed-form solutions limits the functional forms of technologies and preferences that can be considered as well as the degree of heterogeneity between agents. This especially holds if the aim is to derive a balanced growth path along which the economy grows at a constant rate in the long-run. Numerical forecasts about the impact of specific policies on the long-run growth performance of an economy require a more disintegrated approach. Different economic sectors react very differently to energy shortages, policies and pollution. In order to reproduce the diverse reactions within a model, different production technologies - especially with respect to the importance and substitutability of energy as an input - have to be considered. Yet, this sectoral heterogeneity more often than not prevents the derivation of closed-from solutions and requires to resort to simulations. While the fast growing capacity of computers allows to run more and more sophisticated simulations, one crucial problem remains. Due to the complex structure of the models, it is difficult to trace the effects of policies and scarcities on economic performance through the model. Consequently, economic processes sometimes seem to take place in a black-box. 
In this paper we aim to give an introduction to both types of modeling approaches in the context of endogenous growth. Section 2 deals with highly-stylized frameworks in the tradition of especially Romer (1986) and Acemoglu (2002). We give an overview of the topics treated which is separated according to the input and output side, i.e. pollution, of energy use. We present the most important insights obtained from the analyses. Regarding disintegrated models employing an endogenous growth engine, we give an overview of the literature in section 3. Section 4 provides an outlook on future research, before a short summary in section 5 closes the paper.

\section{Theoretical framework}

In the context of energy use and climate change, the endogenous growth literature's aim is to identify policies and incentives that lead to sustainable development, i.e. "'development that lasts' and that is supported by an economically profitable, socially responsive and environmentally responsible energy sector with a global, long-term vision" (IEA 2001: 4). More specifically, sustainable development is associated with non-decreasing utility in the long-run.

Regarding the use of fossil energy sources the absolute limit on exhaustible energy reserves seems to give rise to a fundamental dichotomy: On the one hand, the limited availability of fossil energy will eventually induce energy prices to rise. It is often postulated that this price increase will lead to a downturn of economic activities, as it was, for example, observed after the first oil crises. In this respect, the scarcity of nonrenewable energy sources is seen as negative for welfare and sustainability. On the other hand, the unavoidable decrease of fossil energy use that follows from it's limited stocks will reduce $\mathrm{CO}_{2}$-emissions and thereby the threat to the environment. In this sense, the limited availability of exhaustible resources is positive for welfare and sustainability. So, it might seem as if a fundamental tension existed between economic and environmental prosperity.

This view of the problem does, however, not take into account that the scarcity induced rise of energy prices fosters incentives to develop alternative energy sources and to reduce the resource intensity of production (Bretschger 2010). The endogenous growth literature identifies the mechanisms at work and shows that rising resource scarcity might even lead to an increase in growth if the resulting efficiency gains are sufficiently strong. It aims at showing ways to reduce the dependency on fossil energy, promote alternative investment in carbon-free energy sources, more resource-extensive production processes and possibly sectoral change towards less energy intensive goods. 
In the following we will discuss whether the tension between resource use and scarcities of resources on the one hand and pollution on the other hand necessarily exists and which mechanisms could overcome it. We start by shedding some light on the input side of the energy sustainability debate in the endogenous growth literature. Specifically, we focus on approaches that incorporate energy from fossil sources whose supply is absolutely limited in the long-run. Subsequently, we take a look at the output problem of the energy debate, i.e. the pollution generated by the input of energy. The section is closed by a short look at policies aiming at an optimal extraction and pollution path.

\subsection{The input side}

A large variety of approaches exist in the endogenous growth literature that analyze the dependency on scarce natural inputs like energy stemming from fossil sources. Most of these models do, however, not focus exclusively on energy, but rather more generally on natural resources that can be of renewable or non-renewable nature. Energy in this sense is just one possible type of these resources. Due to the high degree of abstraction in these models, sectoral differences in energy-intensity and substitutability play a role, yet not to the same extent as in the disintegrated approaches.

The models introduced in this subsection can be distinguished along different lines. First, we can differentiate according to the engines that drive growth. These may include the accumulation of physical and/or human capital, learning by doing and technological progress. Second, models differ with respect to the number of sectors they consider. In the simplest case, the economy features only one production sector - as, for example, in AK-type models (see e.g. Gradus and Smulders 1993, Baranzini and Bourguignon 1995, Withagen 1995 and Smulders and Gradus 1996). Yet, especially more recent models often encompass a number of sectors that produce goods, conduct R\&D and/or extract resources.

In the one-sector economies of many early approaches the only way to reduce fossil energy use is to invest in some other type of capital, for example by investing in physical capital (see Groth and Schou 2007). Yet, with respect to physical capital this substitution is necessarily limited by the second-law of thermodynamics. ${ }^{1}$ So, some other source of accumulable asset is required. However, without considering explicitly human capital or R\&D, accumulation usually results from either learning by doing in the tradition of Romer (1986) or from public infrastructure following Barro (1990). Either explanation has its merits and empirical evidence can be found that supports that

both factors attribute to growth. ${ }^{2}$ With respect to the energy sector, especially learning by doing has been extensively analyzed empirically and, for example, MacDonald and 
Schrattenholzer (2001) support that cumulative experience influences production costs favorably. Nevertheless, these approaches remain unsatisfying as they seem to suggest that there is no room - or rather no need - for private activities to promote a change in the energy regime. Yet, the evidence on learning curves as well as on public investment also shows that induced productivity increases might be limited (see e.g. Barro and Sala-i-Martin 1991 and Thompson 2008). Consequently, the interesting task lies in the exploration of incentives to develop new technologies and, specifically, to promote R\&D in less (fossil) energy-intensive technologies.

Much of the literature in this area builds upon the papers of Romer (1990), Grossman and Helpman (1991) and Aghion and Howitt (1992) who explicitly model research activities. Incentives to engage in research stem from profits arising from monopolistic competition in combination with patents on the blueprints developed. In their basic versions, these models consider either horizontal differentiated goods (Romer 1990), that could be interpreted as new product varieties, or vertically differentiated goods (Grossman and Helpman 1991, Aghion and Howitt 1992), that can be thought of as process innovations. As the mechanisms driving growth in these two models are quite similar, we focus in the following on only one of the two - the Romer-type approach.

Growth in this model is driven by the expanding variety of goods available as intermediates in the production of final output or, alternatively, for consumption purposes. Research leads to the development of new product varieties. As R\&D is considered to be labor-intensive, labor $L_{R}$ is often considered to be the only rival input to research (e.g. Scholz and Ziemes 1999, Pittel 2002, Schou 2002). ${ }^{3}$ Furthermore, research productivity is assumed to depend positively on the amount of past research. In the simplest version of this 'standing on the shoulders of giants', research is linear in spillovers from past research, such that the production function for new intermediates reads

$$
\dot{N}=\frac{d N}{d t}=\gamma L_{R} N
$$

where $\gamma$ is a productivity parameter and $N$ is the 'number' of intermediates that equals the stock of knowledge from past research.

The assumption of linearity of research in spillovers from past research has often been heavily criticized - not only in the context of resource economics. It is often argued that past knowledge only fertilizes new research subject to decreasing returns ('fishing out' phenomenon). If, however, research is less than linear in knowledge spillovers, productivity growth peters out in the long-run. In this case, long-run growth requires population growth, such that the increase in the size of the labor force compensates the decreasing returns from research. ${ }^{4}$ A similar compensating force is required if research is modeled to depend on the input of exhaustible resources. As the input of non-renewable 
resources has to decline in the long-run, linear spill-over from past knowledge are in this case not sufficient to generate sustainable productivity growth.

In the Romer (1990) model, incentives to develop new product varieties arise from profits earned by selling these varieties on a monopolistic market. Competition in the production of new products is prevented by patent protection of new blueprints. Combination of the expanding variety approach with Ethier (1982) production functions (resp. Dixit-Stiglitz preferences, Dixit and Stiglitz 1977) forms the basis for the sustainability of long-run growth in these models. Based on the work of Spence (1976), the tendency of diminishing returns with respect to individual products is overcome due to gains from specialization, i.e. the larger the variety of goods, the more productive the aggregate. The aggregate output of intermediates in efficiency units (i.e. the physical output of intermediates weighted by their productivity) can be written as

$$
\tilde{X}=\int_{0}^{N} x_{i}^{\alpha_{1}} d i, \quad 0<\alpha_{1}<1
$$

with $x_{i}$ denoting the output of the individual intermediates' varieties. Given that all varieties are produced with the same production technology, $x_{i}=x$ holds in equilibrium and (2) reduces to $\tilde{X}=N^{1-\alpha_{1}} X$ with $X=\int_{0}^{N} x_{i} d i$. So, even if the amount of intermediates $X$ is constant over time (i.e. $g_{X}=\frac{\dot{X}}{X}=0$, where $g_{X}$ denotes the growth rate of $X$ ) increasing specialization due to the development of new varieties gives rise to growth of the aggregate in efficiency units. ${ }^{1}$ In the context of sustainable energy use, this implies that long-run growth might be feasible even if the input of energy is constant or decreases over time. This shown by, for example, Scholz and Ziemes (1999) in which $\mathrm{R} \& \mathrm{D}$ leads to an increasing variety of capital inputs $(x(i)=K(i))$. The positive productivity effect of this increasing variety can overcome the scarcity of the essential input of natural resources (e.g. fossil energy) in the production of final output $Y$

$$
Y=A \int_{0}^{N} K_{i}^{\alpha_{1}} d i L_{Y}^{\alpha_{2}} R^{\alpha_{3}}=N^{1-\alpha_{1}} f\left(K, L_{y}, R\right), \quad \alpha_{2}, \alpha_{3}>0, \sum_{k=1}^{3} \alpha_{k}=1
$$

where $L_{Y}, K$ and $R$ are the inputs of labor, aggregate capital and exhaustible resources in final output production.

Although $R \& D$ is in this case not directly aimed at reducing the non-renewable input, research decreases the energy-intensity of output as it increases the productivity of all factors. Scholz and Ziemes show that long-run growth under the increasing scarcity

\footnotetext{
${ }^{1}$ To see this, consider that the growth rate of $\tilde{X}$ is given by $g_{\tilde{X}}=\left(1-\alpha_{1}\right) g_{N}+g_{X}$. For a constant $X$ (i.e. $\left.g_{X}=0\right)$ and increasing specialization $\left(g_{N}>0\right), \tilde{X}$ grows at a positive rate: $g_{\tilde{X}}=\left(1-\alpha_{1}\right) g_{N}>0$.
} 
of non-renewable inputs is feasible in these types of models given that research is sufficiently productive and the implementation of new ideas increases marginal productivity enough. The drag on growth which is due to the decreasing input of an exhaustible factor is overcompensated by the rising number of differentiated outputs and the induced increase in productivity. This type of model shows one basic mechanism by which resource scarcity can be overcome in the long-run. It is, however, not entirely satisfying as the forces at work are not resource- or energy-specific.

Pittel (2002) models research to be directly aimed at increasing the variety of scarce material intermediates. Material intermediates in this model are a composite of virgin renewable resources $R$ and recycled materials $W_{R}$. Final output production is thus given by

$$
Y=A \int_{0}^{N}\left(W_{R_{i}}^{\beta} R_{i}^{1-\beta}\right)^{\alpha_{1}} d i L_{Y}^{\alpha_{2}}=N^{1-\alpha_{1}} g\left(W_{R}, Z, L_{Y}\right) .
$$

The last expression on the RHS in (4) shows clearly that, although research is directly aimed at increasing the efficiency of scarce material inputs, it affects all inputs symmetrically due to the assumed Cobb-Douglas production technology, i.e. technological development is Hicks-neutral. As the elasticity of substitution between different inputs is unity, natural resource enhancing technological progress has the same implications as technological progress in the Scholz and Ziemes (1999) model in (3). Research in this case does not induce substitution processes between natural and man-made inputs and therefore leaves the optimal input mix unchanged. The same holds for the model of van Zon and Yetkiner (2003) who consider an economy in which intermediates are produced from capital services and energy. In their model research leads to an enhancement of the quantity as well as the quality of intermediates. Assuming exogenously increasing energy prices, the authors show that the rise in energy prices has a negative effect on growth. Due to the increase in the costs of intermediate production, the profitability of research declines along with the profitability of intermediates production.

In reality different economic sectors display very different resource intensities and the interesting question is not only whether technological development can overcome the non-increasing input of natural resources but also how the rising scarcity of natural resources might affect sectoral production, the sectoral composition of an economy as well as the direction of research. To answer these types of questions models are needed that not only comprise different sectors but also allow for endogenous sector shares and directed technological change. One option by which to attain these goals is a more flexible production function of the CES-type. Acemoglu (2002) has shown that combining the Romer (1990) approach with a CES-technology induces technological change that is directed at the relatively scarcer input. In case neither factor of production is 
non-essential, i.e. if the elasticity of substitution between factors is below unity, the resulting long-run growth path is stable.

Smulders and de Nooij (2003) were among the first to employ Acemoglu's approach to an energy economics model in which, however, the supply of energy is exogenously given. Di Maria and Valente (2008) extend the analysis to the case of an endogenous supply of non-renewable resources. They show that Acemoglu's result remains valid in a model with capital and non-renewable resources as inputs to production. In the longrun equilibrium, research is purely resource-augmenting. Pittel and Bretschger (2010) generalize the analysis to the realistic case of heterogeneous resource intensities across production sectors. The production function for final output in their model reads

$$
Y=\left(\tilde{X}_{t}^{\frac{\nu-1}{\nu}}+\tilde{Z}_{t}^{\frac{\nu-1}{\nu}}\right)^{\frac{\nu}{\nu-1}}, \quad \nu<1
$$

where $X$ and $Z$ are two types of intermediates that are produced in two sectors that differ with respect to the resource intensity of production. In contrast to (3) and (4), the elasticity of substitution between the two inputs to final production is less than unity. Without increases in resource productivity, output growth would peter out due to the limited availability of natural resources. In the case of exhaustible resources like fossil energy (as in Pittel and Bretschger), output would even go to zero in the long-run.

As in the previous models, this drag on growth and the level of output can be overcome by research induced productivity increases. In contrast to the previous models, however, the direction of technological change matters. Due to the CES production technology, technological progress is not Hicks-neutral as in the Cobb-Douglas case but rather sector-specific. Pittel and Bretschger show that resource-intensive sectors need not vanish in the long-run. Due to increasing resource scarcity, the profitability of conducting research in these sectors increases. As a result, productivity is enhanced which overcompensates the drag of declining resource inputs. The shares of resource intensive sectors remain unchanged in the long-run, solely productivity develops differently across sectors with resource-intensive sectors conducting more research. Anecdotal empirical evidence seems to support this result, as investment in energy related R\&D has been observed to increase faster than research activities in general (see e.g. OECD 2008 for Hungary). Also, the International Energy Agency (IEA) emphasizes the large potential for improving energy efficiency in the energy-intensive sectors (see IEA 2008, p. 112).

The result of a long-run bias of technological change towards the energy/nonrenewable resource is confirmed by André and Smulders (2008). In contrast to the previous papers they specifically consider dynamics of extraction costs. Models that assume either no or constant extraction costs typically show that energy prices (ex- 
traction) increase (decreases) continuously over time. For the long-run this prediction seems straightforward due to the rising scarcity of resources. In the short-run, however, empirics have shown that energy prices might well decrease. Andre and Smulders show that this phenomenon may well be in line with the endogenous growth literature. Calibrating their model such that improvements in mining efficiency are sufficiently large and factor-augmenting technological change is initially neutral, the energy share in factor income can decrease temporarily. Yet, over time the decrease in extraction costs is overcompensated by the increasing scarcity of energy which induces a bias towards energy-saving technological change. In the long-run, the energy share in factor income is again constant, thus confirming the results of the previous literature.

Most of the literature on endogenous growth and resources focuses on the input of one type of resource, for example fossil energy, without considering substitution processes between non-renewable and renewable or backstop resources. One of the few exception is Grimaud et al. (2007). Grimaud and co-authors consider the input of energy as a mix of fossil energy and energy stemming from a 'backstop' resource. This backstop resource is produced from final output and knowledge by a concave production technology. Research is dedicated at the overall efficiency of energy use as well as the efficiency of the backstop resource. It is shown that, as to be expected, the growth path of the economy is characterized by substitution out of fossil energy towards the backstop resource. As fossil and backstop fuels are assumed to be imperfect substitutes, both resources are, however, employed in the long-run. Due to the assumption that research cannot directly be aimed at fossil fuels, nothing is said with respect to the optimality of investing in the efficiency of the non-renewable resource.

\subsection{The output side}

Burning fossil fuels is the main cause for the emission of the most important greenhouse gas $\mathrm{CO}_{2}$. According to the EIA (2009: 111), the energy-related global carbon dioxide emissions will rise by 1.4 per cent annually between 2006 and 2030. Regarding the recent IPCC (2007) projections of future global warming, the so-called best estimates for six emissions scenarios are in the range 1.8 to 4 degree Celsius at 2090-2099 relative to 1980-1999. This warming may cause a substantial sea level rise; the snow cover is forecasted to contract and it is likely that the frequency of weather extremes will continue to rise.

Despite these forecasts of severe consequences of climate change, most of the models introduced in the previous section solely concentrate on the input side of non-renewable resource, resp. fossil energy, use. Pollution is often neglected in this strand of literature 
(see e.g. Scholz and Ziemes 1999, Grimaud and Rougé 2003 and Pittel et al. 2010). The most straightforward explanation for this neglect is probably that the focus of the models is on the very long run. As the input of fossil resources declines over time, so does the generated flow of pollution, thus making pollution from fossil sources a temporary problem rather than a problem that becomes more and more threatening over time.

Among those papers who consider environmental externalities that explicitly consider pollution from non-renewable inputs are Schou (2000, 2002) and Grimaud and Rougé (2005). The pollution flow $P$ that is modeled as a function of the extracted exhaustible resources

$$
P=P(R), \quad P_{R}>0
$$

affects household's utility and/or production negatively. As shown by Schou (2002), whether or not pollution is modeled as a flow (as in (7)) or stock $S$

$$
\dot{S}=P(R)-n(S)
$$

does not matter in the long-run as long as the pollution stock has sufficient degenerative capacity, $n(S)$, and ecological thresholds, $\bar{S}$, after which the environmental degradation becomes irreversible, play no role.

Pollution can harm either production and/or the utility of households. In case production is affected negatively, the positive contribution of resources to output is diminished, thus lowering the social return to resource extraction. In case households are affected, their intertemporal utility is lowered. Assuming that households, resp. a succession of generations, live forever and derive utility from consumption $C$ and disutility from pollution $P$, their utility would thus be given by

$$
\int_{0}^{\infty} U\left(C_{t}, P_{t}\right) e^{-\rho t} d t
$$

with $\rho>0$ being the rate at which households discount future utility. The utility function satisfies the usual properties $\left(U_{C}>0, U_{C C}<0, U_{P}<0, U_{P P}>0\right)$.

Sustainability in the sense of non-decreasing welfare usually requires pollution to be non-increasing at least in the long-run. For pollution stemming from non-renewable sources this is automatically fulfilled as the extraction of non-renewable resources necessarily decreases over time (i.e. $g_{P}=P_{R} g_{R}<0$ ) - although a temporary increase in extraction and thereby an increase in pollution is conceivable. Nevertheless, pollution gives rise to externalities that lead to suboptimal growth and can therefore call for environmental policies (see next subsection). 
Pollution can, however, not only be generated directly from the input of fossil energy but also from other economic variables that increase in a growing economy, i.e. output or the input of capital. The flow of pollution in these cases would be given by

$$
P=P(Y), \quad P_{Y}>0, \quad \text { resp. } \quad P=P(K), \quad P_{K}>0 .
$$

In a growing economy, this pollution would increase over time $\left(g_{P}=P_{i} g_{i}>0, i=\right.$ $K, Y)$ in the absence of environmental policies or abatement and therefore threaten sustainability. Equivalently, pollution that accumulates over time and only degenerates at a very low (or zero) rate $(n(S) \rightarrow 0)$ or exceeds ecological thresholds is not compatible with sustainable development. The endogenous growth literature on pollution deals extensively with these types of pollution and derives a number of policy rules that aim at internalizing pollution externalities and assure for sustainability. As this discussion is, however, only indirectly related to the energy sustainability debate, we do not discuss these cases here at length. The interested reader is referred to Pittel (2002) who gives an introduction to the different types of pollution and policies and also provides a review of the relevant literature.

\subsection{Energy and resource policies}

Most of the literature in the field of endogenous growth and non-renewable resources assumes that resource extraction is conducted by perfectly competitive firms such that resource prices follow the Hotelling rule. Thus, in the absence of other resource related market failures as pollution, the resource sector itself does not warrant governmental intervention. Typical non-resource-related market failures that arise in the models of Subsection 2.1 are related to research spillovers and monopolistic competition in the intermediates goods sectors. As a result, optimal policies rules comprise the standard policies for the Romer (1990) model.

Regarding policies aiming at influencing the level and time path of resource extraction, a number of policies are discussed in the literature. Some papers derive the need for such policies from pollution caused by the use of fossil resources (e.g. Schou 2000, 2002; Groth and Schou 2007), others abstract from pollution, yet justify the policy analysis from targets currently discussed in the field of energy and climate policies (Pittel and Bretschger 2010). Besides resource taxes these policies include taxes on capital gains and interest income (Groth and Schou 2007). Assuming that the political defined aims are to save on resource use and to support resource-extensive sectors, Pittel and Bretschger (2010) furthermore check whether or not these goals can be attained by the provision of productive public goods and labor/research subsidies. 
Let us take a closer look at resource taxation as this policy is not only among the most frequently analyzed (e.g. Groth and Schou 2007 and Pittel and Bretschger 2010) but also among the most commonly adopted instruments. In the context of climate change, the usual aim of resource taxation is to reduce fossil energy use at present and in the near future in order to lengthen the extraction phase and move emissions of $\mathrm{CO}_{2}$ at each point in time closer to the absorptive capacity of the environment. It is shown that resource taxation only affects long-run growth if the rate of taxation changes over time. Given a constant (ad valorem) tax rate, resource taxation leaves the intertemporal arbitrage of resource owners unaffected. Taxation in this case only leads to a rent transfer from the producer to the taxing institution. A rising rate of resource taxation on the other hand induces the speed of resource extraction to rise as resource owners foresee the future decrease in the non-taxed share of resource revenues. Consequently, postponing resource extraction requires to tax resource use at a decreasing rate - thus the endogenous growth literature confirms the result of the 'green paradox' (Sinn 1982, 2008).

It should be noted that while a decreasing tax rate slows down resource extraction and has therefore the potential to increase growth (see e.g. Groth and Schou 2007), this might not always be optimal from a welfare perspective. Grimaud (2004) and Grimaud and Rougé (2005) show that the optimality of this result depends on the preferences of households.

Consider a model in which pollution has a negative amenity effect on utility (as in (8)) and fossil resources are an essential input to final goods production. The optimal environmental policy rule derived by Grimaud and Rougé for this case reads

$$
g_{\tau}=-\frac{U_{P} P_{R}}{U_{C} F_{R}}\left(g_{\left(U_{P} P_{R}\right)}-\rho\right)
$$

where $F_{R}$ is the marginal product of the resource in production. Clearly, the rate at which the tax rate should grow over time depends crucially on the relative disutility of resource extraction, $\frac{U_{p} P_{R}}{U_{C} F_{R}}$. The higher the marginal disutility from pollution generated by resource extraction is compared to the marginal utility of consumption that can be produced from the extracted resource, the faster the tax rate should grow. Whether the optimal tax should, however, increase or decrease over time depends on the term in brackets (as the relative disutility of resource extraction is strictly negative). Given that the marginal disutility of pollution decreases over time or increases only moderately, the growth rate of the tax is optimally negative - implying the previously described shift of resource extraction from the present into the future. Yet, if the marginal disutility from pollution increases over time ( $\operatorname{such}$ that $g_{\left(U_{P} P_{R}\right)}>\rho$ ), a positive growth rate of the tax can be optimal. 
Whether or not environmental policy is called at all in the case of pollution from fossil energy use depends crucially on the shape of the production and utility functions. Employing a Cobb-Douglas production function for final output and a CRRA utility function, Schou $(2000,2002)$ shows that environmental policy is not required to attain the optimal growth path. It should be noted though that this result is due to the specific choice of technology and preferences in Schou's paper and does not carry over to more general specifications (Grimaud 2004).

\section{CGE-models}

In contrast to the endogenous growth models of the previous section, CGE-models that integrate energy markets usually strive to provide scientists as well as politicians with numerical estimations of policy impacts for specific economies or world regions. While the models of Section 2 aim primarily at deriving general policy impacts by identifying the relevant transmission channels, the models of this section focus on giving concrete policy advise. As already stated in the introduction, this sometimes comes at the expense of a seemingly black-box approach where policy enters on the one side and economic implications on firms, sectors and households emerge at the other side. Tracing policy effects through the model becomes difficult if not impossible due to the multitude of interrelations.

Integrating endogenous growth into these models has proven to be rather challenging due to not only the more complex economic structure but also due to implementation problems when simulating these models. As a consequence a large part of the CGEliterature has relied on exogenous growth processes (e.g. Burniaux et al. 1992, Nordhaus 1992 and Peck and Teisberg 1992). The drawback to this set-up is the same as in the analytically solvable models: The engine of growth is independent of energy policies such that no feedback effects of policy on the growth engine arise. As CGE-models are usually constructed in order to allow estimations of policy effects, leaving an important transmission channel of environmental policy out of the picture can lead to wrong conclusions and policy advise. Empirical evidence that energy price changes - as, for example, induced by policy measures - affect innovation (e.g. Newell et al. 1999, Popp 2001, 2002 and Bretschger 2010) and thus the economies' growth engine, support this view.

Models in which growth is driven endogenously comprise approaches that incorporate learning by doing as well as R\&D and gains from specialization. The drawback to learning by doing is again that it does not disclose the decision making processes 
behind technological development and investment in research but rather takes technological progress as an automatism. CGE-models that include learning by doing are, for example, Messner (1997), van der Zwaan et al. (2002) and Gerlagh et al. (2004).

Beyond learning by doing a number of papers also include investment in R\&D (e.g. Goulder and Schneider 1999, Nordhaus 2002 and Popp 2004). ${ }^{5}$ The only paper known to us that incorporates investment in $\mathrm{R} \& \mathrm{D}$ and gains from specialization as in Romer (1990) is, however, Bretschger et al. (2010). Their paper predicts the effects of Swiss carbon policies on consumption, welfare, and sectoral development where growth is driven endogenously by a sector-specific increasing specialization in capital varieties. Due to the incorporation of gains of specialization in an endogenous growth model with research, their economy reacts differently to energy, resp. carbon, taxation than an economy with exogenous growth. The growing capital stock not only provides a substitute for energy but also raises productivity. While substitution helps to decrease fossil energy use, i.e. helps to achieve the environmental goals, the simultaneous productivity increase attenuates detrimental effects on growth and welfare. As Bretschger et al. employ a model which is closest to the Romer (1990) model on which we focused in Section 2, we present their approach in a little more detail.

The model comprises 10 'regular' economic sectors plus an oil sector and an energy sector. Production technologies are nested and firms in each sector conduct sectorspecific $R \& D$. In their research activities firms employ labor, $L$, and a share of sectoral output, $Y_{R \& D}$, as inputs and generate investment in non-physical capital as $I_{N P}$

$$
I_{N P_{t}}=\left[\gamma L_{t}^{\frac{\sigma_{N}-1}{\sigma_{N}}}+(1-\gamma) Y_{R \& D_{t}}^{\frac{\sigma_{N}-1}{\sigma_{N}}}\right]^{\frac{\sigma_{N}}{\sigma_{N}-1}} .
$$

$\sigma_{N}$ is the sectoral elasticity of substitution in the production of non-physical capital. $I_{N P}$ is then combined with investment in physical capital $I_{P}$ and previously accumulated capital to a composite capital stock per firm $K$

$$
K_{t+1}=\left[\gamma I_{P_{t}}^{\frac{\sigma_{I}-1}{\sigma_{I}}}+(1-\gamma) I_{N P_{t}}^{\frac{\sigma_{I}-1}{\sigma_{I}}}\right]^{\frac{\sigma_{I}}{\sigma_{I}-1}}+(1-\delta) K_{t}
$$

where $\delta$ is the depreciation rate of capital. The CES-specification in (11) and (12) allows for a high degree of flexibility and sector specific modeling. Elasticities of substitution vary for sectoral $R \& D$ as well as with respect to sectoral intermediates, final goods and energy production. Also, due to the CES specification, the optimal input mix in R\&D as well as production can react to policy induced price changes. Thus not only the engine of growth but also the direction of technological change, the sectoral structure and also the optimal resource allocation are completely endogenized. 
Typically for a CGE-model, the paper's focus is on numerical policy scenarios for which the impact on a specific economy, in this case Switzerland, is to be estimated. Two taxation scenarios that are modeled to be compatible with actual policy goals are compared with respect to their effects on growth and sectoral structure. In the first scenario, a $\mathrm{CO}_{2}$ tax is levied that is inspired by the reduction scenarios discussed at the UN Climate Change Conference in Copenhagen in 2009. The second scenario builds upon the goal of transforming the Swiss economy into a '2000 Watt society' until 2090.

Bretschger et al. derive results on, among others, the development of welfare, individual sectors and energy use. Due to the model's complexity, the exact channels through which policies are transmitted are hard to follow. Yet, it is exactly the disaggregated nature of the model that allows a precise analysis of sector specific reactions to climate policies that is usually not feasible within the highly-stylized models of section 2. Specifically, sectoral reactions are driven by the differences in investment intensities, in resource intensities and sectoral linkages.

The paper finds that starting from a benchmark scenario with balanced growth and no damages from climate change, a $\mathrm{CO}_{2}$-policy following the Copenhagen Accord entails moderate yet not negligible welfare losses. Welfare losses in case of the 2000 Watt society scenario are predictably lower as this policy is less stringent. This comparison focuses on the costs of climate policy (i.e. the 'costs of action') while an analysis of its benefits, in the form of avoided climate change damages (i.e. the 'costs of inaction'), is left for future research. The integration of the benefits might of course affect the welfare ranking of the two policies due to the different time paths of $\mathrm{CO}_{2}$ emissions.

When comparing the costs of climate policies obtained from different models and also across policies, some caution is advised. The respective degree of disaggregation as well as assumptions regarding production technologies and preferences of course crucially affect the results obtained. Regarding limitations of (and potential biases in) the cost estimations in climate policy models see also Tavoni and Tol (2010).

\section{Future research fields}

Although many topics have been addressed extensively by the endogenous growth literature on sustainability and energy use, there are also aspects that have so far often been neglected. The security of energy supply and ancillary benefits arising from climate policies are two of these topics which, due to their importance, will be addressed in the following. 


\section{Security of energy supply}

In its Green Paper "A European Strategy for Sustainable, Competitive and Secure Energy" (EC 2006: 17-18), the European Commission recognizes that two of the main objectives of Europe's energy policy should be environmental sustainability - which was already addressed in this paper - and the security of supply.

Among the most discussed questions regarding the security of supply are the problem of long-run (non-)availability due to decreasing fossil energy stocks as well as problems arising from market failures like market power or the risk of supply disruptions for, e.g., geo-political reasons. While the first aspect, the exhaustibility of fossil energy, has been at the core of the analysis of Subsection 9.2.1, the second aspect is regularly disregarded by the endogenous growth literature.

A lack of energy security in the second interpretation might give rise to welfare losses. A shortage of energy suppliers, for example, influences the functioning of markets negatively by constituting an oligopoly. Energy supply disruptions, of course, also involve components of other sustainability dimensions. An energy-shortage-induced price increase, for example, tends to have negative social implications. In the long-run perspective, energy security influences especially the incentives to invest in the technological development of alternative energy sources as well as energy saving technologies. Therefore an analysis within the endogenous growth framework could yield interesting results.

Outside the endogenous growth literature, recently several studies have investigated the linkages between pollution and energy security. The IEA (2007) assesses interactions between energy security and climate change. Turton and Barreto (2006) provide a study which examines the interrelations and synergies between climate change mitigation and supply security risk management policies. Furthermore, they investigate the role of technology in achieving these two policy goals. They observe that there are some synergies between policies pursuing the combat of global warming and policies intending to mitigate insecurity of energy supply, but point out that the interaction is complex. Markandya, Golub and Strukova (2003) provide an analysis of energy policy in Russia taking into account energy security and climate change aspects.

\section{Ancillary benefits of climate policies}

In the past, the evaluation of climate policies has mainly focused on the costs and benefits of the mitigation of climate change. Yet, climate policies inducing a decline in the burning of fossil fuels also have additional effects that are often ignored. Among those so-called ancillary effects, i.e. effects which do arise from climate policies, but not 
from the mitigation of climate change itself, are air quality improvements. Appendix A displays some of the pollutants emitted in conjunction with $\mathrm{CO}_{2}$ which are - of course - also mitigated if climate policies reduce the burning of fossil fuels. ${ }^{6}$

A comprehensive analysis of climate change policies should include benefits from the reduction of all types of externalities, i.e. climate-change mitigation benefits (primary benefits) as well as ancillary benefits should be taken into account. For the design of optimal policies this is especially important as ancillary effects often exhibit characteristics which are very different to those of climate change mitigation. While the mitigation of $\mathrm{CO}_{2}$ exerts the global effect of climate change mitigation, the abatement of other pollutants like $\mathrm{SO}_{2}$ or particles has geographically more limited effects. Also the delay between emission of the pollutants and the point of time when they effectively start to harm the environment diverge between the individual pollutants. ${ }^{7}$

The endogenous growth literature has so far mostly ignored these additional benefits, although their inclusion could affect the optimal time path as well as the optimal level of pollution policies substantially. An approach should be chosen that allows to differentiate between long-run and short-run effects of pollution reduction and also takes an international/-regional perspective in order to differentiate between different geographical scopes. To our knowledge, the only paper addressing both questions in an endogenous growth framework is Pittel and Rübbelke (2010) who derive implications for optimal pollution taxation. ${ }^{8}$

Alternatively to the reduction of the burning of fossil fuels, climate can also be protected by the substitution of less carbon-intensive fuels for carbon-intensive ones, e.g. by substituting natural gas for coal. Also with respect to the optimal design of such substitution processes, ancillary effects play an important role since trade-offs may arise. For example, a switch in electricity generation from fossil fuels like oil, gas or coal to nuclear technologies reduces greenhouse gas emissions in the shape of $\mathrm{CO}_{2}$ emissions but raises other negative externalities. External costs of nuclear electricity generation accrue, for instance, from the higher risk of catastrophic accidents in power plants (Ewers and Rennings 1996). Furthermore, the switch from petrol as a fuel for cars to diesel reduces the emissions of $\mathrm{CO}_{2}$ but raises $\mathrm{PM}_{2.5}$ emissions (Mayeres and Proost 2001). When considering the benefits of a change in the energy mix, these types of ancillary benefits - or in this case ancillary costs - should also be considered. 


\section{Summary}

In the past decades the strand of literature employing endogenous growth models to the energy and sustainability debate has made some important contributions to understanding the long-run potential of economies to overcome the scarcity of fossil energy resources and the potential and direction of technological development.

Following the UN's (2001: 19) classifications of the four primary dimensions of sustainable development (economic, environmental, institutional and social), the focus of this paper has been especially on the environmental dimension. More specifically we dealt with challenges arising from the use of non-renewable resources as the burning of fossil energy resources is the main driver of climate change. As these challenges arise from the input side as well as from the output side of energy use, both, source and sink issues, have been addressed.

In this paper we have further differentiated between analytical solvable endogenous growth models and CGE-models that can only be solved by simulations. We have shown that, for economic development and growth to be sustainable, both types of models identify technological progress and efficiency improvements as the main drivers. We have focussed largely on models employing the disintegrated approach of Romer (1990) as this approach models $R \& D$ investments as the result of decision making processes (in comparison to the quasi-automatic efficiency improvements in learning by doing frameworks). Although endogenous growth in many CGE-models still relies largely on learning by doing, we have also presented an approach in which intentional research investments in combination with gains from specialization drive growth.

Beyond questions regarding the use of fossil resources, on which the focus has been in this paper, the endogenous growth literature has also extensively addressed problems regarding the use of renewable resources (see, e.g., Bovenberg and Smulders 1995, 1996, Aghion and Howitt 1998, Grimaud 1999) of which renewable energy sources are one possible type. The use of renewable resources can diminish both source and sink problems simultaneously and therefore the integration of such resources constitutes an important aspects of the analysis of sustainable energy. As the scope of this paper is, however, limited, we have concentrated mainly on the worst case scenario, i.e. a regeneration rate of zero.

\section{Notes}

\footnotetext{
${ }^{1}$ See also Pittel et al. (2010) for a discussion of material balances and their relation to the accumulation of capital.
} 


\footnotetext{
${ }^{2}$ Regarding public infrastructure see, for example, Aschauer (1989), Baxter and King (1993), Easterley and Rebelo (1993), with respect to learning by doing see, for example, Arrow (1962) and Sheshinski (1967).

${ }^{3}$ Alternatively it can be assumed that natural resources and/or capital are additional inputs to research (Groth 2007, Bretschger 2008).

${ }^{4}$ Often this population growth is assumed to be exogenous (leading to so-called semi-endogenous growth, see Jones 1999). For a model with endogenous population growth that depends on economic conditions, see Bretschger (2008).

${ }^{5}$ For a more extensive review of the literature see Bretschger et al. (2010).

${ }^{6}$ An extensive discussion of the divergences between the characteristics of primary and ancillary can be found in Rübbelke (2002) as well as Markandya and Rübbelke (2004).

${ }^{7}$ There is a delay in the reaction of climate to greenhouse gas (GHG) emission changes: "because of the thermal inertia of the oceans, the climate appears to lag perhaps a half century behind the changes in GHG concentrations" (Nordhaus 1994: 4-5). In contrast, ancillary benefits of local/regional air pollution reductions can be largely enjoyed already shortly after the climate policy implementation.

${ }^{8}$ Another growth paper that considers primary and secondary benefits is Bahn and Leach (2008) in which technological development is, however, exogenous. They consider secondary effects of climate policy due to the reduction of $\mathrm{SO}_{2}$ emissions in an overlapping generation model. Also, their model is not analytical solvable, such that transmission channels of secondary benefits and costs are not clearly identifiable.
}

\section{References}

Acemoglu, D. (2002), 'Directed technical change', Review of Economic Studies, 69, 781-809.

Aghion, P. and P. Howitt (1992), 'A Model of growth through creative destruction', Econometrica, 60, 323-351.

Aghion, P. and P. Howitt (1998), Endogenous Growth Theory, Cambridge, Mass.: The MIT Press.

André, F. and S. Smulders (2008), Fueling Growth when Oil Peaks: Growth, Energy Supply and Directed Technological Change, mimeo.

Arrow, K.J. (1962), 'The economic implications of learning by doing', Review of Economic Studies, XXIX, 154-174.

Aschauer, D.A. (1989), 'Is public expenditure productive?', Journal of Monetary Economics, 23, 177-200.

Baranzini, A. and F. Bourguignon (1995), 'Is sustainable growth optimal?', International Tax and Public Finance, 2, 341-356.

Bahn, O. and A. Leach (2008), 'The secondary benefits of climate change mitigation: an overlapping generations approach', Computational Management Science, 5, 233-257.

Barro, R.J. (1990), 'Government spending in a simple endogenous growth model', Journal of Political Economy, 98, S103-S125.

Barro, R.J. and X. Sala-i-Martin (1991), 'Public finance in models of economic growth', Review of Economic Studies, 59, 645-61. 
Baxter, M. and R. King (1993), 'Fiscal policy in general equilibrium', American Economic Review, 83, 315-334.

Bovenberg, A.L. and S. Smulders (1995), 'Environmental quality and pollution-augmenting technical change in a two-sector endogenous growth model', Journal of Public Economics, 57, 369-391.

Bovenberg, A.L. and S. Smulders (1996), 'Transitional impacts of environmental policy in an endogenous growth model', International Economic Review, 37, 861-893.

Bretschger, L. (2010), 'Energy Prices, Growth, and the Channels in Between: Theory and Evidence', CER-ETH Working Paper 06/47, ETH Zürich, revised version March 2010.

Bretschger, L. (2008), 'Population growth and natural resource scarcity: long-run development under seemingly unfavourable conditions', CER-ETH Working Paper 08/87, ETH Zürich.

Bretschger, L., R. Ramer and F. Schwark (2010), 'Long-run effects of post-Kyoto policies: applying a fully dynamic CGE model with heterogeneous capital' CERETH Working Paper 10/129, ETH Zürich.

Burniaux, J.-M., J.P. Martin, G. Nicoletti and J.O. Martins (1992), 'GREEN a multisector, multi-region general equilibrium model for quantifying the costs of curbing $\mathrm{CO}_{2}$ emissions: a technical manual', OECD Economics Department Working Papers, no. 116, OECD Publishing.

Di Maria, C. and S. Valente (2008), 'Hicks meets Hotelling: the direction of technical change in capital-resource economies', Environment and Development Economics, 13, 691-717.

Dixit, A.K. and J.E. Stiglitz (1977), 'Monopolistic competition and optimum product diversity', American Economic Review, 67, 297-308.

Easterley, W. and S. Rebelo (1993), 'Fiscal policy and economic growth: an empirical investigation', Journal of Monetary Economics, 32, 389-405.

EC (2006), A European Strategy for Sustainable, Competitive and Secure Energy, Green Paper, Brussels.

Edenhofer, O., C. Carraro, J. Koehler and M. Grubb (eds), 'Endogenous technological change and the economics of atmospheric stabilisation', Special Issue of The Energy Journal.

EIA (2009), International Energy Outlook 2009, Washington, D.C.

Ethier, W.J. (1982), 'National and international returns to scale in the modern theory of international trade', American Economic Review, 72, 389-405.

Ewers, H.J. and K. Rennings (1996), 'Quantitative Ansätze einer rationalen umweltpolitischen Zielbestimmung', Zeitschrift für Umweltpolitik und Umweltrecht (ZfU), no. $4,413-439$. 
Gerlagh, R., B. van der Zwaan, M.W. Hofkes and G. Klaassen (2004), 'Impacts of $\mathrm{CO}_{2^{-}}$ taxes in an economy with niche markets and learning-by-doing', Environmental and Resource Economics, 28, 367-394.

Goulder, L.H. and S.H. Schneider (1999), 'Induced technological change and the attractiveness of $\mathrm{CO}_{2}$ abatement policies', Resource and Energy Economics, 21, 211-253.

Gradus, R. and S. Smulders (1993), 'The trade-off between environmental care and long-term growth pollution in three prototype growth models', Journal of Economics, 58, 25-51.

Grimaud, A. (2004), 'Note on the Schou's paper: 'When environmental policy is superfluous: growth and polluting resources, Scandinavian Journal of Economics", IDEI Working Papers no. 261, University of Toulouse.

Grimaud, A. (1999), 'Pollution permits and sustainable growth in a Schumpeterian growth model', Journal of Environmental Economics and Management, 38, 249266.

Grimaud, A., G. Lafforge and B. Magné (2007), 'Innovation markets in the policy appraisal of climate change mitigation', IDEI working paper no. 481, University of Toulouse.

Grimaud, A. and L. Rougé (2005), 'Polluting non-renewable resources', innovation and growth: welfare and environmental policy, Resource and Energy Economics, 27, 109-129.

Grimaud, A. and L. Rougé (2003), 'Non-renewable resources and growth with vertical innovations: optimum, equilibrium and economic policies', Journal of Environmental Economics and Management, 45, 433-453.

Grossman, G. M. and E. Helpman (1991), 'Quality ladders in the theory of growth', Review of Economic Studies, 58, 43-61.

Groth, C. (2007), 'A new-growth perspective on non-renewable resources', in L. Bretschger and S. Smulders (eds), Sustainable Resource Use and Economic Dynamics, Springer.

Groth, C. and P. Schou (2007), 'Growth and non-renewable resources: the different roles of capital and resource taxes', Journal of Environmental Economics and Management, 53, 80-98.

IEA (2008), Energy Technology Perspectives: Scenarios 83 Strategies to 2050, OECD, Paris.

IEA (2007), Energy Security and Climate Policy - Assessing Interactions, Paris.

IEA (2001), Toward a Sustainable Energy Future, www.iea.org/textbase/nppdf/free/ 2000/future2001.pdf.

IPCC (2007), Climate Change 2007 - The Physical Science Basis, Cambridge University Press: New York. 
Jones, C.I. (1999), 'Growth: with or without scale effects?', American Economic Review, 89, 139-144.

Markandya, A., A. Golub and E. Strukova (2003), 'The influence of climate change considerations on energy policy: the case of Russia', International Journal of Global Environmental Issues, 3, 324-338.

Markandya, A. and D.T.G. Rübbelke (2004), 'Ancillary benefits of climate policy', Jahrbücher für Nationalökonomie und Statistik, 224, 488-503.

Mayeres, I. and S. Proost (2001), 'Should diesel cars in Europe be discouraged?', Regional Science and Urban Economics, 31, 453-470.

McDonald, A. and L. Schrattenholzer (2001), 'Learning rates for energy technologies', Energy Policy, 29, 255-261.

Meadows, D.H, D.L. Meadows and J. Randers (1972), The Limits to Growth, New York: Universe Books.

Messner, S. (1997), 'Endogenized technological learning in an energy systems model', Journal of Evolutionary Economics, 7, 291-313.

Newell, R.G., A.B. Jaffe and R.N. Stavins (1999), 'The induced innovation hypothesis and energy-saving technological change', The Quarterly Journal of Economics, 114, 941-975.

Nordhaus, W.D. (2002), 'Modeling induced innovation in climate-change policy', in A. Grübler and N. Nakicenovic (eds), Technological Change and the Environment, Resources for the Future, Washington.

Nordhaus, W.D. (1992), 'An optimal transition path for controlling greenhouse gases', Science, 258, 1315-1319.

OECD (2008), GERD Data, titania.sourceoecd.org.

Peck, S.C. and T.J. Teisberg (1992), 'CETA: a model for carbon emissions trajectory assessment', Energy Journal, 13, 55-77.

Pittel, K. (2002), Sustainability and Endogenous Growth, Cheltenham, UK and Northampton, MA, US: Edward Elgar.

Pittel, K., P. Amigues and T. Kuhn (2010), 'Recycling under a Material Balance Constraint', Resource and Energy Economics, 32, 379-394.

Pittel, K. and L. Bretschger (2010), 'The implications of heterogeneous resource intensities on technical change and growth', forthcoming in Canadian Journal of Economics.

Pittel, K. and D.T.G. Rübbelke (2010), Local and Global Externalities, Environmental Policies and Growth, mimeo.

Popp, D. (2004), 'ENTICE: Endogenous technological change in the DICE model of global warming', Journal of Environmental Economics and Management, 48, 742768. 
Popp, D. (2002), 'Induced innovation and energy prices', The American Economic Review, 92, 160-180.

Popp, D. (2001), 'The effect of new technology on energy consumption', Resource and Energy Economics, 23, 215-239.

Romer, P.M. (1990), 'Endogenous technological change', Journal of Political Economy, 98, $71-102$.

Romer, P.M. (1986), 'Increasing returns and long-run growth', Journal of Political Economy, 94, 1002-1037.

Rübbelke, D.T.G. (2002), International Climate Policy to Combat Global Warming An Analysis of the Ancillary Benefits of Reducing Carbon Emissions, Cheltenham, UK and Northampton, MA, US: Edward Elgar.

Scholz, C.M., and G. Ziemes (1999), 'Exhaustible resources, monopolistic competition and endogenous growth', Environmental and Resource Economics, 13, 169-185.

Schou, P. (2002), 'When environmental policy is superfluous: Growth and polluting resources', Scandinavian Journal of Economics, 104, 605-620.

Schou, P. (2000), 'Polluting non-renewable resources and growth', Environmental and Resource Economics, 16, 211-227.

Sheshinski, E. (1967), 'Tests of the "Learning by Doing" hypothesis', The Review of Economics and Statistics, 49, 568-578.

Sinn, H.-W. (2008), 'Public policies against global warming', International Tax and Public Finance, 15, 360-394.

Sinn, H.-W. (1982), 'Taxation, growth and resource extraction - A general equilibrium approach', European Economic Review, 19, 357-386.

Smulders, S. and R. Gradus (1996), 'Pollution abatement and long-term growth', European Journal of Political Economy, 12, 505-532.

Smulders, S. and M. de Nooij (2003), 'The impact of energy conversation on technology and economic growth', Resource and Energy Economics, 25, 59-79.

Spence, M. (1976), 'Product selection, fixed costs, and monopolistic competition', Review of Economic Studies, 43, 217-235.

Tavoni, M. and R.S.J. Tol (2010), Counting only the Hits? The Risk of Underestimating the Costs of Stringent Climate Policies, mimeo.

Thompson, P. (2008), Learning by doing, mimeo.

Turton, H. and L. Barreto (2006), 'Long-term security of energy supply and climate change', Energy Policy, 34, 2232-2250.

UN (2001), Indicators of Sustainable Development: Guidelines and Methodologies, www.un.org/esa/sustdev/natlinfo/indicators/indisd/indisd-mg2001.pdf. 
Van der Zwaan, B.C.C., R. Gerlagh, G. Klaassen and L. Schrattenholzer (2002), 'Endogenous technological change in climate change modelling', Energy Economics, 24, 1-19.

Van Zon, A. and I.H. Yetkiner (2003), 'An endogenous growth model with embodied energy-saving technical change', Resource and Energy Economics, 25, 81-103.

Withagen, C. (1995), 'Pollution, abatement and balanced growth', Environmental and Resource Economics, 5, 1-8. 


\section{Appendix}

\section{A Selection of Pollutants Emitted in Conjunction with $\mathrm{CO}_{2}$ and Ex- amples of Impacts (Rübbelke 2002)}

\begin{tabular}{|c|c|c|c|}
\hline Pollutant & Sources & Health Effects & Visibility and Other Effects \\
\hline $\begin{array}{l}\text { Carbon } \\
\text { Monoxide } \\
(\mathrm{CO})\end{array}$ & $\begin{array}{l}\text { fuel combustion; indus- } \\
\text { trial processes; natural } \\
\text { sources like wildfires }\end{array}$ & $\begin{array}{l}\text { reduction of oxygen delivery to } \\
\text { the body's organs and tissues; vi- } \\
\text { sual impairment; reduced work } \\
\text { capacity; reduced manual dexter- } \\
\text { ity; poor learning ability; diffi- } \\
\text { culty in performing complex tasks }\end{array}$ & $\begin{array}{l}\text { acceleration of the greenhouse ef- } \\
\text { fect indirectly by reactions with } \\
\text { other substances }\end{array}$ \\
\hline Lead $(\mathrm{Pb})$ & $\begin{array}{l}\text { fuel combustion; metals } \\
\text { processing }\end{array}$ & $\begin{array}{l}\text { adverse affection of the kidneys, } \\
\text { liver, nervous system, and other } \\
\text { organs; neurological impairments } \\
\text { such as seizures; mental retarda- } \\
\text { tion, and/or behavioral disorders; } \\
\text { changes in fundamental enzy- } \\
\text { matic, energy transfer, and home- } \\
\text { ostatic mechanism; high blood } \\
\text { pressure and subsequent heart dis- } \\
\text { ease }\end{array}$ & $\begin{array}{l}\text { deposition on the leaves of plants, } \\
\text { and with it, representing a hazard } \\
\text { to grazing animals }\end{array}$ \\
\hline $\begin{array}{l}\text { Methane } \\
\left(\mathrm{CH}_{4}\right)\end{array}$ & $\begin{array}{l}\text { burning of natural gas; } \\
\text { coal mining; oil produc- } \\
\text { tion; decomposition of } \\
\text { waste; cultivation of rice; } \\
\text { cattle breeding }\end{array}$ & & $\begin{array}{l}\text { acceleration of the greenhouse ef- } \\
\text { fect; contributes to increased level } \\
\text { of tropospheric ozone }\end{array}$ \\
\hline $\begin{array}{l}\text { Nitrogen Ox- } \\
\text { ide }\left(\mathrm{NO}_{\mathrm{x}}\right)\end{array}$ & $\begin{array}{l}\text { combustion processes in } \\
\text { automobiles and power } \\
\text { plants; home heaters and } \\
\text { gas stoves also produce } \\
\text { substantial amounts }\end{array}$ & $\begin{array}{l}\text { irrigation of lungs and causing } \\
\text { lower resistance to respiratory in- } \\
\text { fections; increased incidence of } \\
\text { acute respiratory diseases in chil- } \\
\text { dren }\end{array}$ & $\begin{array}{l}\text { gaseous } \mathrm{NO}_{\mathrm{x}} \text { absorbs light, re- } \\
\text { duces the visual range; important } \\
\text { pre- cursor to ozone and acidic } \\
\text { precipitation; impact on PM con- } \\
\text { centration; causing severe injury } \\
\text { to plants; acceleration of the } \\
\text { greenhouse effect by contributing } \\
\text { to ozone generation }\end{array}$ \\
\hline $\begin{array}{l}\text { Nitrous Ox- } \\
\text { ide }\left(\mathrm{N}_{2} \mathrm{O}\right)\end{array}$ & $\begin{array}{l}\text { burning of fossil fuels; } \\
\text { agricultural soil manage- } \\
\text { ment }\end{array}$ & & $\begin{array}{l}\text { acceleration of the greenhouse ef- } \\
\text { fect; reduces the stratospheric } \\
\text { ozone layer }\end{array}$ \\
\hline Ozone $\left(\mathrm{O}_{3}\right)$ & $\begin{array}{l}\text { no direct emission but } \\
\text { formation by the reac- } \\
\text { tion of VOCs and NOx; } \\
\text { therefore, ozone is indi- } \\
\text { rectly caused by combus- } \\
\text { tion processes }\end{array}$ & $\begin{array}{l}\text { increased hospital admissions and } \\
\text { emergency room visits for respira- } \\
\text { tory causes; higher susceptibility } \\
\text { to respiratory infection and lung } \\
\text { inflammation; aggravation of pre- } \\
\text { existing respiratory diseases; sig- } \\
\text { nificant decreases in lung func- } \\
\text { tion; increase in respiratory symp- } \\
\text { toms; irreversible changes in the } \\
\text { lungs }\end{array}$ & $\begin{array}{l}\text { reduction in agricultural and com- } \\
\text { mercial forest yields; reduced } \\
\text { growth and decreased survivabil- } \\
\text { ity of tree seedlings; plants' higher } \\
\text { susceptibility to diseases, insect } \\
\text { attack, harsh weather and other } \\
\text { environmental stresses; accelera- } \\
\text { tion of the greenhouse effect }\end{array}$ \\
\hline $\begin{array}{l}\text { Particulate } \\
\text { Matter (PM) }\end{array}$ & $\begin{array}{l}\text { emission directly by a } \\
\text { source or formation by } \\
\text { the transformation of } \\
\text { gaseous emissions; com- } \\
\text { bustion processes cause } \\
\text { direct emissions }\end{array}$ & $\begin{array}{l}\text { premature death; increased hos- } \\
\text { pital admissions and emergency } \\
\text { room visits; increased respiratory } \\
\text { symptoms and disease; decreased } \\
\text { lung function; alterations in lung } \\
\text { tissue and structure and in respi- } \\
\text { ratory tract defence mechanisms; } \\
\text { lung cancer }\end{array}$ & $\begin{array}{l}\text { important cause of reduced vis- } \\
\text { ibility; airborne particles cause } \\
\text { soiling and damage to materials }\end{array}$ \\
\hline $\begin{array}{l}\text { Sulfur Diox- } \\
\text { ide }\left(\mathrm{SO}_{2}\right)\end{array}$ & $\begin{array}{l}\text { burning of coal and oil; } \\
\text { metal smelting and other } \\
\text { industrial processes }\end{array}$ & $\begin{array}{l}\text { effects on breathing; respiratory } \\
\text { illness; alterations in the lungs' } \\
\text { defences, and aggravation of exist- } \\
\text { ing cardiovascular disease }\end{array}$ & $\begin{array}{l}\text { a major precursor to } \mathrm{PM} \text {, which } \\
\text { is a main pollutant impairing vis- } \\
\text { ibility together with } \mathrm{NO}_{\mathrm{x}} \text {, a main } \\
\text { precursor to acidic deposition }\end{array}$ \\
\hline
\end{tabular}




\title{
BC3 WORKING PAPER SERIES
}

\author{
Basque Centre for Climate Change (BC3), Bilbao, Spain
}

The BC3 Working Paper Series is available on the internet at the following addresses:

http://www.bc3research.org/lits_publications.html

\section{http://ideas.repec.org/s/bcc/wpaper.html}

BC3 Working Papers available:

2009-08

2009-09

2009-10

2009-11

2010-01

2010-02

2010-03

2010-04

2010-05

2010-06

2010-07

2010-08

2010-09

2010-10

Ibon Galarraga and Anil Markandya: Climate Change and Its Socioeconomic Importance

Julia Martin-Ortega and Anil Markandya: The Costs of Drought: the Exceptional 2007-2008 Case of Barcelona

Elena Ojea, Ranjan Ghosh, Bharat B. Agrawal and P. K. Joshi: The Costs of Ecosystem Adaptation: Methodology and Estimates for Indian Forests

Luis M. Abadie, José M. Chamorro, Mikel Gonzáez-Eguino: Optimal Investment in Energy Efficiency under Uncertainty

Sara L. M. Trærup, Ramon Arigoni Ortiz and Anil Markandya: The Health Impacts of Climate Change: A Study of Cholera in Tanzania

Mikel González-Eguino, Ibon Galarraga and Alberto Ansuategi: Carbon leakage and the Future of Old Industrial Regions after Copenhagen

Roger Fouquet: Divergences in the Long Run Trends in the Price of Energy and of Energy Services

Giacomo Giannoccaro and Julia Martin-Ortega: Environmental Concerns in Water Pricing Policy: an Application of Data Envelopment Analysis (DEA)

Roger Fouquet: The Slow Search for Solutions: Lessons from Historical Energy Transitions by Sector and Service

Ibon Galarraga, Mikel González-Eguino and Anil Markandya: Evaluating the Role of Energy Efficiency Labels: the Case of Dish Washers

Luis M. Abadie, Mikel González-Eguino and José M. Chamorro: Optimal Abandonment of Coal-Fired Stations in the EU

Dirk Rübbelke and Stefan Vögele: Impacts of Climate Change on European Critical Infrastructures: The Case of the Power Sector

Roger Fouquet: The Sustainability of 'Sustainable' Energy Use: Historical Evidence on the Relationship between Economic Growth and Renewable Energy

Karen Pittel and Dirk Rübbelke: Energy Supply and the Sustainability of Endogenous Growth 